\title{
The Acquisition of Language: Evidence in Syntax
}

\author{
Jakov Proroković \\ Frane Malenica \\ *University of Zadar, English Department
}

Abstract

This paper aims to discuss the two main approaches to language acquisition and present the main ideas behind the nativist and the usage-based account. The concomitant argument between the two sides has been present in linguistics ever since the proposal of innateness was provided by the paradigm of mainstream generative grammar (Chomsky 1965). In order to contribute to the ongoing discussion, we will attempt to outline the main challenges that the both theoretical strands are faced with and provide an overview of syntactic evidence provided by linguists whose work was devoted to understanding the mechanisms of language acquisition. Our goal is to analyze the insights provided by the phenomena such as syntactic bootstrapping, poverty of the stimulus, multiple argument realizations and non-canonical syntactic constructions and argue that integrating these findings into a usage-based framework (Tomasello 2000, 2003 \& 2009) or various instances of Construction Grammar (Goldberg 1995 \& 1996, Fillmore Kay \& Fillmore 1999, van Trijp 2016, Steels 2011, inter alia) provides a more plausible and comprehensive explanation of the processes responsible for language acquisition.

Keywords: Acquisition of Language: Evidence in Syntax

\section{Introduction}

Although the origins and the complexity of language were discussed long before Chomsky's entrance into the world of linguistics, it is only after his response to Skinner (Chomsky 1959) that the processes underlying the language acquisition have become the subject of intense linguistic debate. The mystery of the language acquisition that has puzzled psychologists, linguists and even philosophers (Skinner 1957, Chomsky 1959, Descartes 1984) was rooted in the fact that language appears to be reserved only for the human race. The diverging views on language acquisition between Chomsky and Skinner have retained a similar form until today and they stem from different accounts of mechanisms by which humans acquire language. The central problem in their disagreement was evident in the importance they ascribed to linguistic environment and the input to child speech. The analysis of evidence in syntax becomes interesting for our paper since it adequately reflects the relationship between input and speech. Naturally, the evidence put forward can sometimes be regarded as disputable or problematic, especially when approached from alternative theoretical paradigms. In the paper, we examine some of the familiar syntactic evidence (Goldberg 1995 \& 2006, Pinker \& Jackendoff 2005, Jackendoff 2007 \& 2008, Tomasello 2009) and outline the main traits of two broad theoretical accounts of language acquisition: the usage based-account and the nativist account. One theoretical strain posits grammatical competence to be innate, capacity which is human-specific. The alternative approach to language acquisition puts emphasis on the children's general cognitive processes and regards the process of acquisition as incremental development. The main goal of our paper is to assess the viability of theoretical arguments provided by both sides, especially those concerning the evidence in grammar, and to rule out those contentions which do constitute a sensible framework for the analysis of language acquisition. Of course, the final verdict on the adequacy of the theoretical alternatives remains to be reached by the linguistic community, which is why this paper aims only to acknowledge their work and offer a humble estimation of it. In section 1, we provide a summary of the main features of nativism and the central issues related to this standpoint. Section 2 deals with its theoretical opposition, 
the usage-based approach, advocated by Tomasello (among many others), in which the acquisition of syntax is seen as a piecemeal process enabled by the children's analogical and inductive skills. In section 3, we turn to the evidence in input. The so-called "Poverty of the Stimulus" argument is examined with the focus on acquisition of verbs. The acquisition of verbs in regards to their transitivity characteristics is scrutinized in section 4 , where the alternative reasoning to the one of syntactic bootstrapping is provided. The link between meaning and syntax is inspected in section 5 , especially in relation to children's concept understanding. Section 6 deals with the Construction Grammar and Parallel Architecture approaches to syntax-semantics mapping and provides challenges to the classical lexicon-syntax dichotomy. We also look at noncanonical syntactic constructions and their relevance for challenging the nativist assumptions. Section 7 contains he final discussion along with the conclusion.

\section{The nativist approach to language acquisition}

Noam Chomsky is undoubtedly one the most renowned names in the field of linguistics in general and one of the pioneers of the nativist approach to language acquisition. The discussion on mechanisms behind language acquisition dates back to Chomsky's response to Skinner's idea about children's verbal behaviour being predictable because it is acquired via external reinforcing stimuli (Chomsky 1959). At the times, Chomsky's response might have been considered radical, and yet today, the argumentation that there is something innate about our capacity to acquire and process language is considered legitimate in linguistic circles. One of its basic assumptions is that human language is overly complex for such an effortless process of acquisition that the child demonstrates. Simple perception of the environment and exposure to language cannot account for such rapid acquisition. Hence, grammar as a complex set of rules that govern the language use must be innate. One of the ideas behind it was that all languages share the fundamental underlying similarities, such as the presence of grammatical categories like nouns and verbs in all languages, which would surely be explained by genetic predetermination. The only way that one can challenge this idea of innateness is to offer a "general learning strategy" which would account for acquisition, which, according to Chomsky, has not yet been offered (2006: 183). Universal Grammar emerges as a theory that accounts for these "linguistic universals" (Cook and Newson 2007).

However, the notion of UG is not universally accepted by the linguistic community, as was recently reflected by, among others, Evans and Levinson (2009), Everett (2005), Müller (2013). Evans and Levinson (2009) present several aspects in which languages differ fundamentally rather than superficially ${ }^{1}$ and one of the dissimilarities between languages that comes they mention is word order. Some languages have SVO order, other SOV order and there are even significant changes within one language through time. English, for instance, "has changed from a free-word order, highly inflected, topicprominent language, as its sister German remains to this day, to a fixed-word-order, poorly inflected, subject prominent language, all in less than a millennium." (Pinker 1995: 235).

As anticipated, languages differ at the level of phonology, morphology and semantics (Evans and Levinson 2009). Most of these differences are often characterized as superficial by the advocates of UG. Nevertheless, the grammatical variation across languages extends beyond different word-orders. Some of these apparent differences could hardly be classified as superficial. For instance, "many languages lack an open adverb class" (Evans and Levinson 2009: 434). Languages like Lao lack an adjective class. Word classes such as coverbs, classifiers, positionals or ideophones are not employed in English (or in the case of classifiers occur marginally). As Evans and Levinson further demonstrate, certain constraints that are found in English do not apply to languages such as Italian or Russian, which not only refutes the linguistic universals, but also points out the anglo-centric position from which Chomsky operated (Evans and Levinson 2009: 437). Most importantly, not all languages can be interpreted in terms of constituent structure. Evans and Levinson give an example of Latin sentence which would be represented better through a dependency module, since a tree diagram would appear

1 The reader should bear in mind that the ideas put forth in Evans \& Levinson (2009) are often regarded as controversial. For a critical assessment of their claims, see, inter alia, Nevins 2009, Keenan \& Stabler 2010, Abels \& Neelman 2010, Reuland \& Everaert 2010; for a counter-reply to criticism, see Levinson \& Evans 2010. 
senseless (due to the arrangement of words it would have crossing lines). As they postulate, "There can be constituent structure without recursion, but there can also be hierarchical relations and recursion without constituency" (Evans and Levinson 2009: 440).

If the nativists' claims were taken to extreme, they could be taken to imply that children are linguistically competent from the earliest stages of their lives, but the lack of performance is obviously due to underdeveloped motor skills, practice, insufficient input and other performative aspects of language use. Needless to say, the assumption of complete linguistic competence from birth challenges the functional bearing that general cognition ought to have in the language acquisition. According to the nativist paradigm, the input is only relevant in a sense in which it provides the child with something to apply its inborn grammatical categories and rules to. The supposed innate mechanism was ultimately named LAD (language acquisition device).

Within the faculty of language, two major components were defined - Faculty of language-broad sense (FLB), which encompasses the "conceptual intentional" and "sensory motor" systems, and the Faculty of language-narrow sense (FLN), (Hauser et al. 2002). Both of these systems constitute certain parts of general cognition. Nevertheless, FLB includes FLN, which is undeniably the controversial element in the scheme. "FLN is the abstract linguistic computational system alone, independent of the other systems with which it interacts and interfaces" (Hauser et al. 2002: 1571). Nevertheless, the fact that the two internal systems are exclusively attributed to human race is what is most emphasized in their work. As they put it, "although homologous mechanisms may exist in other animals, the human versions have been modified by natural selection to the extent that they can be reasonably seen as constituting novel traits, perhaps exapted from other contexts (e.g. social intelligence, tool-making)" (Hauser et al. 2002: 1572). The latter part of the quote was afterwards the target of most criticism, as it effectively states that the supposed faculty of language is completely autonomous and has no links to general cognition or intelligence, although this has been the central issue in previous discussions as well. Again, FLB is not as rigorously separated from cognition, which makes the theory a bit contradictive, but doubtlessly more bulletproof to further criticism. Notwithstanding, the nativist theory is rather clear on these points today and the intelligence part is taken out of the acquisition equation. By drawing an analogy with animals and "imbeciles" which acquire language, Chomsky indeed argues intelligence to be a separate mechanism (2006: 9). The argumentation put forward is that of special "device", which evolution has resulted in, and which equips us with language and grammar from the point of birth. Although FLB is less restrictive to mechanisms shared with the rest of the animal kingdom, Hauser et al. maintain FLN to be a human privilege. $^{1}$

The existence of FLN is often justified by what is argued to be the property of all languages - recursion or "a capacity for discrete infinity" (Hauser et al. 2002: 1573). This would mean that humans have the capability of producing the infinite number of grammatical sentences. Jackendoff delineated this further by stating that "a set of rules is called 'recursive' if the rules can apply to their own output an unbounded number of times and thereby can produce an unlimited number of expressions from a finite set of primitives" (2011: 591). It follows from the argumentation that any sentence has the possibility of being infinitely long regardless of its vocabulary limitation. Naturally, for this to be true, language's syntactic properties must allow such possibilities. The usual example for infiniteness or recursivity are the embedded sentences. For example, the sentence: "He reckons that his brother told him that Sarah believed that...", can potentially continue to infinity. Here, the possibility of infiniteness is induced only through one conjunction. The case for a biologically endowed language faculty is also weakened by claims in Everett (2003) that the Amazonian language Pirahã does not allow recursion as this was regarded as one of the fundamental features of language in Hauser et al. (2002)2.

1 For a more detailed discussion on this topic, see Jackendoff (2011), Mendívil-Giró (to appear).

2 It should be mentioned that the question of recursion in Pirahã is far from being conclusively answered and we will treat the issue as open. For arguments denying the existence of recursion in Pirahã, see Nevins et al. 2009a \& 2009b; for arguments defending Everett's original claim, see Everett 2007, Futrell et al. 2016. 
According to Hauser et al., "it seems relatively clear, after nearly a century of intensive research on animal communication, that no species other than humans has a comparable capacity to recombine meaningful units into an unlimited variety of larger structures, each differing systematically in meaning" (2002: 1576). Certainly, the communicative systems can be found among various animal species, but something as intricate as language has remained unobservable outside the human species. Therefore, highlighting the absence of recursion in the animals' communicative systems is justified and yet redundant, just as it would be redundant to claim that 3D technology will not be available to the viewer via his colourless television. Moreover, it is not clear how the examination of such abstract concept like recursion and infiniteness among animals can be productive for our discussion. The comprehension of the term requires at least human cognitive capacities, which tells us that the application of the same would require similar capacities. In addition, the property of boundlessness expands beyond the realms of language. It is observed and discussed in most natural sciences: chemistry, physics, mathematics etc. Thus, even if the infiniteness is linguistically observable, there is no reason why it should the separating factor between the so-called LAD and other general cognitive capacities. Pinker and Jackendoff have criticized most of the argumentation regarding the recursion provided by Hauser et al. (2002), especially it being exclusively tied to FLN and the evidence of its existence (Pinker and Jackendoff 2005). The recursion can be observed or interpreted in other human senses, such as human visual cognition. As they explain, the outside world is perceived as being made of discrete elements, which can be joined together to form larger constituents, and the sequences which are observed as pairs or clusters can be endless. It is always possible to generate larger constituents from various elements (ibid, 2005). Since the universe itself is infinite and humans tend to categorize, it can be expected that the so called "discrete infinity" is perceivable wherever. If we were to gracefully integrate the property of recursion into the nativist approach, we ought to attribute the property to FLB rather than the FLN.

\section{The usage-based approach to language acquisition}

The usage-based approach, as advocated by Tomasello, emphasizes nurture over nature (Tomasello 2000, 2003 \& 2008). Within the approach, child's general cognition is highlighted in the acquisition of language, rather than asserting the linguistic capacity as being innate. According to Tomasello, children do not reach the phase of language acquisition until the age of one. Until then, they will have developed skills such as intention-reading (functional dimension) and pattern finding (grammatical dimension), both of which are actually cognitive functions usually unrelated to language at all (2008: 69). Tomasello considers intention-reading to be species-specific, something the nativists render extremely important. However, one might say that intention-reading is unobservable in primates because it implies reading the intentions of others and it seems that intentional action is reserved only for species capable of intending something, which means it is cognitively advanced. Assuming that intentional action does exist among other primates or animals, it is hardly plausible that the rest of the animal kingdom meets the cognitive requirements for taking the goals of others into consideration or for understanding the fact that others are in fact doing something intentionally. The acquisition of any linguistic item depends on such understanding. The gap between the understanding part and the acquisition part, which is called the "chasm" by Chomsky, and the bridging of this gap is where the two theories differ fundamentally.

"For example, almost all infants communicate by pointing before they have acquired any productive language, and many also use some kind of iconic or conventionalized gestures as well... This suggests that human pointing and other gestures may already embody forms of social cognition and communicative motivation that are unique to the species, and that are necessary as a first step on the way to linguistic conventions both phylogentically and ontogenetically" (Tomasello 2008: 70).

Similarly to Chomsky, Tomasello acknowledges the fact that certain mechanisms are unique to humans. Nevertheless, these mechanisms are rather the byproduct of the more evolved cognitive system in humans. Naturally, the cognition or intelligence could be regarded innate to a certain extent, but the term itself is best avoided because of its species-specific implications. While intention-reading is regarded uniquely human by Tomasello, this is rather a "side-effect" of a more advanced general cognition as noted previously. This account places importance on the pre-linguistic communication, upon 
which the linguistic communication is then built (Tomasello 2008). The example of bridging the "chasm" can be a young child pointing to the television and, in a lack of a better or not yet acquired word, saying "Daddy" to express its desire for watching television. The linguistic symbols such as "TV" or "turn on" will only become available to the child afterwards as markers of his intention. The child's mastering of the new words will require him/her to understand the fact that they lack the necessary vocabulary, the need to learn it and, at the same time, to have the ability of using only partially linguistic communication to reach their goals. A similar example is that of acquiring any other word for a particular object. For instance, in the acquisition of the word "table", the bridging of the "chasm" is less obvious because the table is visually observable as a physical manifestation and the parent's usage of the word is accompanied with the gaze towards it. In this case, the bridging requires less cognitive activity since perception rather than abstract thinking is what is required for the acquisition of the "new" notion. As Crain and Thronton explain it:

"Advocates of the usage-based account highlight the availability of relevant cues in the input to children. These cues serve as the basis for the generalizations that children form about language. These generalizations are formed using general purpose learning mechanisms including distributional analysis, analogy, cut and paste operations, and the like. The products of these learning algorithms are 'shallow' records, which children keep of their linguistic experience" (2012: 186).

Finally, by the time the child has learned to produce the whole utterance, to turn off or on the television, the child already understands the motive and the reference. This means that the child understands the reason for turning on the television and what the entire process (turning on of the television) which is being referred to means. This is precisely why Tomasello renders a complete utterance to be the smallest communicative unit, since one can express full intention only via such construction. Thus, in order to understand how language acquisition operates, one needs to understand the ways by which the grammar operates. It might seem that the first thing that the child learns in a language is a word, but according to this account it is quite the opposite. While the word may be what is first uttered, it surely is not what is first learned. The child first listens to the conversations, utterances and with the help of observation and deduction, the child tries to figure out the meaning of an individual word. It is the function of the word in a sentence, as well as the meaning of the surrounding elements, that will guide the child's analytical attempt to uncover the word's meaning (Tomasello 2008: 74). Clearly, one cannot extrapolate the meaning of a word just by analyzing one utterance. The child remembers the series of utterances in which the particular word was mentioned and, like in mathematics, the child uncovers the meaning of the constant (the word) with the help of several equations (utterances).

Lastly, the second cognitive skill of central importance to language acquisition, according to Tomasello, is pattern-finding. The first difference between pattern-finding and intention-reading is that pattern finding is spread among all primates (Tomasello 2008: 86). Pattern-finding, sometimes called the pattern-recognition, is the analytical process of finding regularities and extracting the relevant data form the input, which is language in this case. Recursion seems to be viewed as a by-product of the human's cognitive constrains as well as the pragmatic limitations related to discourse. Before assuming the universality of grammar, one must first take into consideration the fact that cognitive skills and the same analytical thinking is universal as well, which makes it plausible to regard the universality of grammar as a by-product of the stated processes. As Pinker puts it when referring to the similar word-order across languages,

"The second counter explanation that one must rule out before attributing a universal of language to a universal language instinct is that languages might reflect universals of thought or of mental information processing that are not specific to language... Perhaps subjects precede objects because the subject of an action verb denotes the causal agent (as in Dog bites man); putting the subject first mirrors the cause coming before the effect" (1995: 235)

The analytical process is also accounted for in the proposal called Conservative Learning (Snyder 2007). At the earliest stage of acquisition, children are assumed to be reproducing the expressions that they encountered in their linguistic environment (Crain and Thornton 2012: 187). According to this view, innate language capacity is redundant in the process of learning. Mastering the new linguistic constructions relies completely on input and the learners' experience. Conservative 
learning seems to be in alignment with Tomasello's claims, which is why he remains theoretically defensive of such a learning model.

\section{Poverty of the stimulus}

One of the most discussed and perhaps the most challenging issue within the usage-based theory is question of verb acquisition. Naturally, not every word-class presents the same amount of difficulty upon its acquisition. Verbs seem to be conceptually more demanding than nouns, partially because the comprehension of them, as stated previously, requires more than simple perception and the understanding of the corresponding actions (Tomasello and Brandt 2009: 1994). Indeed, nouns may denote abstract concepts, but the nouns encountered or learned in the earliest stages of childhood are often those denoting nearest objects. In order to examine the acquisition of verbs, Tomasello and Brandt conducted a research relying on the diaries that were supposed to be led by children's parents in which they would keep track of the 10 instances where the targeted verbs were used, that is, 10 utterances that contained the verbs. Finally, the results showed that the average time for children's usage of the acquired verb in ten instances was around one month (2009: 116). In 75\% of the cases children would use different agents or locations with the same verbs. At first glance, it may seem that the nativist account benefits from such findings, since one month's time is hardly a long period for such accomplishment if the child's average daily use of language is taken into consideration. According to this perspective, these results indicate that children are truly flexible in their language use or the use of verbs ${ }^{1}$. Nevertheless, the issue remains on whether children come to know more than they could have learned from the input and whether this piece of evidence supports it.

The argument of children coming to know much more than they could have simply absorbed through input is often emphasized by the nativist paradigm. The logic behind the generative linguistic tradition states that the capacity to go beyond the input provided in the environment proves that people have grammatical categories and rules already inborn. Flexibility, however, is not necessarily a proof of innateness hypothesis. The real issue might be the one of productivity, which is very different from flexibility. Children's capacity of great flexibility can prove to be within the boundaries of what has been provided in the input, especially if we were to talk about the syntactic or morphological flexibility. Indeed, children seem to learn a new manner in which the verb can be used every time they hear it. However, productivity implies that something is used in a completely different or "new" way, whether morphologically or syntactically. As Tomasello and Brandt put it, "And so flexibility with particular verbs does not signal lexically general productivity across all verbs, unless one has evidence that the flexibility is due to a child's creative generalization and not simply to a reproduction of adult flexibility with each particular verb individually" (2009: 120). The main point that Tomasello and Brandt are aiming at is that it is impossible to know what the child has produced anew without having the records of the input the child encountered. Normally, such records ought to contain the input of the last several days the child has heard, rather than a single one. This leads us to the conclusion that any attempt of investigating productivity without the complete records of the input is futile.

In some cases, the acquisition of number words has also proven to be as troublesome for the child as the acquisition of verbs. In order to for acquisition of a number word to occur, such as "four" for instance, the child must understand the meaning behind it, the meaning which is nothing less abstract than that of a verb. Of course, it is necessary that the child learns to understand the difference between regular nouns or words and those indicating numbers. In order for that to occur, the child's awareness of the fact that the "four" symbolizes "fourness" is mandatory and although seemingly trivial, how they attribute the meaning to the word remains a mystery. Syrett et al. (2012) provide an explanation closer to the nativist perspective. The argument is that children clearly need to have certain concepts, such as cardinality and ordinality, already innate (cardinality marking the number of things that are contained somewhere and ordinality marking a particular sequence the number is a part of which). Uncovering the meaning of a word becomes inaccessible through merely syntactic

1 However, it needs to be noted that such characterizations or assessments of one's flexibility are always subjective or arbitrary, even when put forth by scholars such as Tomasello. 
context (Syrett et al. 2012: 187). Such words are then learned in games that have the counting context, and children can easily understand what the number denotes. For example, someone pointing to dolls and saying: Look at those three dolls.

A particularly convincing argument going against the nativist line of thought regarding this argument comes from Bod (2009) and van Cranenburgh et al. (2016). One of the main claims of Bod (2009) is that the linguistic input is not as underdetermined as is usually assumed. The results of the application of the computer model in Bod (2009), known as the Unsupervised Data-Oriented Parsing (U-DOP), onto language learning indicate that the knowledge of grammatical constraints can be learned from the input without postulating any innate linguistic knowledge, i.e. that children could hypothetically derive their own generalizations about grammaticality of certain syntactic constructions relying solely on the input they receive. The results provided by these models represent a major argument in favour of the usage-based approaches (inter alia, Goldberg 1995 \& 2006, Bybee 2006, Tomasello 2008)1.

\section{Syntactic bootstrapping}

One of the reasons why the acquisition of verbs is often discussed is because a verb's lexical meaning is inseparable from the syntactic characteristics of a sentence. Moreover, the relationship between the verb's position within a sentence and its lexical meaning seems to work bilaterally. For instance, verbs are often labelled as either transitive or intransitive and the labelling stems from the relationship between the verb and a nearby object, or better to say - the way the verb's meaning is influenced by that object. One issue, easily verifiable, is the order by which children acquire the language and is generally agreed upon. Since the first thing that the baby produces is the string of sounds (babbling), phonological development is observed first and is then followed by lexical (one-word stage), morphological, syntactic (full sentence stage) and finally pragmatic development (O'Grady \& Whan Cho 2016) Nevertheless, the debate is on whether the sequence is as clear-cut as argued. For instance, how is it possible that the lexical development precedes the syntactic if the verb's meaning becomes determined by the syntactic environment in the sentence? One explanation is provided by the nativists - the child must have been equipped with full syntax from birth, but the demonstration of the innate knowledge is postponed due to practical reasons - how is the child supposed to demonstrate innate grammar without being able to form a full sentence first. Another explanation is provided by those advocating the usage-based account - innate syntax is not necessary at all because the child is intelligent enough to infer the lexical meanings by using skills previously mentioned (cf. §2).

The proposal that children are equipped with innate knowledge of grammatical categories that helps them deduce meaning and acquire language effortlessly, is called syntactic bootstrapping (Brown: 1957). More accurately, the innate syntactic knowledge is applied to the received input. There are several different explanations for the origins of the syntactic bootstrapping, one of which is structure-mapping account and it states: "On this account, syntactic bootstrapping begins with an innate bias toward one-to-one mapping between NPs in sentences and semantic arguments of predicate terms. Given this bias, children gain some syntactic guidance for verb interpretation as soon as they can identify some nouns in sentences" (Messenger et al. 2015: 357). One-to-one mapping refers to the children's ability to recognize that a certain verb refers to the two nouns in its surroundings, that is - the child understands the possible roles of nouns as either "agents" or "patients". For example, parents may speak about the ski trip they took some time ago in front of a toddler, and since the trip is not occurring in the present in front of a toddler, he/she relies on whatever information of the event that can be extracted only from the linguistic input. In a sentence "Jack yelled at Tom", the toddler might notice the fact that there are two participants in question, while in "Tom left", the number of participants is reduced to one (the intransitive "leaving"). "Implicit learning of these linguistic-distributional facts could permit children to establish an initial lexical entry for a verb, including its syntactic properties and aspects of its semantic structure (two participant-roles vs. one), but leaving unspecified its semantic content.

1 It is also worth mentioning that some aspects of U-DOP described in Bod (2009), namely the MPSD (Most Probable tree generated by the Shortest Derivation), feel reminiscent of the 'Good Enough' approach described in Ferreira et a. (2002) and Ferreira and Patson (2007). 
If children create such entries, and retain them over time, then these linguistic observations could guide later inferences about each verb's event-derived semantic content"(Messenger et al. 2015: 357). The experiment was conducted on children that were 22 months old. The researchers invented the verb "blick" for the purposes of the two phased experiment. In the first phase of the experiment, children were exposed to whether transitive or intransitive forms of the verb by watching two women discussing some event that was not related to the present. During the second phase children were supposed to pick one of the two actions presented upon hearing the isolated verb (find "blicking") - one woman was raising the leg of another (two-participant event), while in other, the two woman did not mind each other in their actions (one-participant event) (Messenger et al. 2015: 359). In the end, the results showed that the children exposed to the dialogues using the transitive "blick" during the first phase ("Bill was blicking a duck"), stared longer at the two-participant event during the second phase, and for those that were hearing the intransitive "blick" ("Bill was blicking") looked longer at the one-participant event (Messenger et al. 2015: 364).

Similar effects in acquisition of verbs are reported in Goldberg et al. (2004) and Boyd and Goldberg (2009). The results based on a spoken corpus consisting of utterances produced by mothers and their children show that the acquisition of a particular syntactic construction (e.g. a ditransitive construction) typically involves a few verbs which instantiate the prototypical relationship between the verb and its arguments within that construction and these few verbs constitute the majority of the tokens in the corpus. This allows the learners to associate the meaning predicated by the verb with the meaning of the entire construction and, thus, make generalizations which allow for further creative uses of the construction using other verbs.

The results seem tosuggest that the children are truly able to extract the information about the verbs by simply listening to language. Basically, children gather the linguistic clues that will aid them in uncovering the meaning of the verb in question. This type of learning is called distributional learning. It is a type of learning where the clues, that are taken in different instances from different syntactic and semantic contexts, are linked to together to uncover the meaning of the verb in question. In other words, every time when the particular word is mentioned, the child memorizes the way of its usage and maps it together with the information from all the previous mentioning of the word. When it comes to acquisition of verbs, a study by Theakston et al. (2004) has shown that there is no significant difference in the acquisition between the semantically more complex verbs and those that are used on a general basis (phrasal verbs such as find, make, go etc.). Naturally, one would assume that these might appear more often, especially when it comes to speech in children. However, while general verbs did appear more frequently in children's speech, the ratio was still the same as it would have been in adult language (Theakston et al. 2004: 90). It seems that the children's language reflected the input. The studies covered by this paper indicate that children are indeed capable of drawing conclusions from language alone and that they rely heavily on the input. If we take into consideration children's usage of cognitive skills within the learning process, as well as the role of the input, it becomes unclear how the argument of "bootstrapping" becomes necessary for the explanation of acquisition. Innate knowledge would be a redundant addition to a child whose learning is distributional and thus it would also be redundant in the unlocking of the mystery of language acquisition.

\section{Syntax-semantic interface}

We have so far analysed the connection between the meaning and syntax in the acquisition of verbs, or more precisely, how the verb's meaning is influenced by syntax. According to Chomsky, the grammar is unrelated to meaning: "Grammar is best formulated as self-contained study independent of semantics..." (2002: 102). This is somewhat expected because the nativist account separates the innate grammar from input, to which grammar is then applied (essentially the child's acquisition comes down to the acquisition of a particular lexicon). When grammar is treated separately from meaning, the proposal that any demonstration of language, is a language acquired, even when nonsensical, becomes valid. For instance, children with cognitive disabilities often speak nonsensically, probably because their interpretation and understanding of the world is different from usual. Moreover, there are other possible reasons for the nonsensical language. Certain linguists that oppose the nativist standpoint, have proposed that "English-speaking children lack what they call the (pragmatic) 
Concept of Non-Shared Assumptions (CNSA), i.e., the notion that "speaker and hearer assumptions are always independent." As long as children lack this concept, they will not consistently take their hearer's assumptions to be different from their own, and thus they will sometimes fail to distinguish common ground contexts from speaker beliefs-only contexts, leading to incorrect article use" (Lillo-Martin \& Muller de Quadros 2011: 634). Thus, the proper usage of language depends on the understanding of it. Ultimately, the issue whether something has been acquired or not, regardless of the proper usage and understanding, becomes a matter of perspective, something that should be avoided in science and which is why we examine the issue further in continuation. Certain evidence suggests that the "understanding" part does not accompany this "articulatory" part fully. For instance, 6-year-old children find the acquisition of telicity problematic, that is, they are incapable of discerning telic from atelic events - meaning that they reportedly fail to detect whether the event in question has ended or not (Yin \& Kaiser 2013: 457). Hence the predicament of whether we can truly argue that something has been acquired regardless of the lack of comprehension.

\section{Parallel Architecture and Construction Grammar}

One of the most intriguing recent developments in the issue of architecture of language comes from Ray Jackendoff's Parallel Architecture (PA) (Jackendoff 2007 \& 2011, Jackendoff \& Audring 2016). This approach represents a step away from the syntactocentric models of linguistic models in mainstream generative grammar by regarding language as being made up of three independent generative levels - phonological, syntactic and semantic, connected via interfaces and by rejecting the strict lexicon-grammar dichotomy (Jackendoff 2007).

While PA may not tackle the issue of language acquisition directly, the evidence that Jackendoff provides upon explaining language processing can surely be applied within the theory of acquisition. The fact that the language needs to be processed in order to be acquired is one the implications of usage-based approach. The difference between the mainstream generative approach and PA is well observed in their approach to sentence building. In the generative tradition, sentence building is viewed as accumulative process, where grammar appears to be working step-by-step. For instance, one constituent combines with another to form a new one, which can be further combined with something else and the process, if needed, can supposedly continue indefinitely. The problematic implication of such perception on sentence building is that meaning is built step-by-step as well. If the mediator between sound production and the production of meaning is syntax, and grammar supposedly operates step-by-step, than the production of meaning must operate in the same way. Such approach to syntax and meaning is severely undermined by phenomena such as constructional idioms and the so-called 'syntactic nuts', like the N-P-N construction (Culicover \& Jackendoff 2005, Jackendoff 2008). Building meaning step-bystep implies that syntactic structure is built first, after which the integration of lexemes (units equipped with meaning) follows with the goal of creating a meaningful sentence, the meaning of which is revealed at the end. As Jackendoff puts it, "The classical architecture, by contrast, implicitly claims that combinatorial thought is impossible without language, because structured semantics relies completely on syntactic combinatoriality. This leaves it a total mystery how other primates manage to do the complex things they do, both in the physical world and in their social environment" (2007: 7). The meaning, instead, is probably a by-product of a mutually combinatorial syntax-semantics relationship, rather than the simple "syntactic combinatoriality". For illustration, Jackendoff provides an example where transitivity exposes this meaning influenced syntax. The verb "devour" is a transitive verb, which means that it requires at least two participants for the action - someone who is devouring and someone who is being devoured (2007: 10). The fact that the sentence requires a direct object proves that the semantic characteristics of the verb govern the rest of the sentence, direct object of which is an inevitable prospect. Object as such is the syntactic operator imposed by the meaning itself.

Similarly, Jackendoff uses the idiom "kick the bucket" to challenge the generative approach to grammar. This particular example is interesting as it reveals a non-correlative relationship between the meaning that would be deduced step-by-step and the actual meaning "to die". Of course, this idiom is not an isolated case of such a relationship. In fact, all genuine idioms are characterized by "idiomaticity" (meaning cannot be deduced from the idiom's constituents). Such idioms are found and identified across other cultures and languages. In the Russian linguistic tradition they are recognized as 
phraseological fusions (Vinogradov 1986), while in the Anglo-Saxon tradition as idioms of decoding (Makkai 1972). Idioms such as "white elephant", or "spill the beans", are textbook examples of these semantically non-motivated structures. Again, the existence of partially lexically filled idioms, i.e. idioms with an open syntactic slot (such as jog X's memory, send X to the cleaners), poses a great challenge for the dictionary-and-grammar model prominent in the generative grammar. On one hand, these syntactic patterns should be stored within the lexicon/dictionary component of the language faculty as they are idiosyncratic and have non-compositional meaning, but on the other hand, they are completely productive and regular, which is why they should be a part of the grammar/syntax module. It would seem that the only plausible conclusion is to reject the division of language into syntax and lexicon and regard it as a continuum with various degrees of schematicity, which is problematic for the nativist accounts, but represents one of the foundations of PA and Construction Grammar $(\mathrm{CXG})^{1}$.

Research has also shown that children store plural nouns they use frequently as separate lexical items in their mental lexicons (Jackendoff 2011: 590), meaning that the redundancies are an integral part of the mental lexicon. Jackendoff is equally critical of the traditional approach to phonology-syntax relationship, the traditional approach being that there is no relationship. According to him, a sentence like "Sesame Street is a production of the Children's Television Workshop" (2007: 5), testifies that there is a correlation indeed, which is evident through the analysis on both phonological and syntactic level:

$$
\text { Syntax: [Sesame Street] [is [a production [of [the Children's Television Workshop]]]] }
$$

Phonology: [Sesame Street is a production of] [the Children's Television Workshop] or

[Sesame Street] [is a production] [of the Children's Television Workshop]

The aim of this analysis is to expose the fact that the constraints exist on the phonological level. One cannot choose to pronounce a particular utterance in whichever manner they please. Certain linguistic conventions require certain level of abidance, for both pragmatic and comprehensive reasons. Besides, it is clear that these phonological constraints somewhat correspond to syntactic ones. Indeed, the two patterns obviously differ. However, even in such case, phonological manifestation of utterance is still guided both syntactically and semantically to a certain level. It would sound rather awkward if someone pronounced the utterance in the following way:

[Sesame] [Street is a] [production of the Children's] [Television Workshop]

Another important aspect of PA is the disapproving stance towards the idea of grammar as a separate linguistic component. Likewise, the acquisition of grammar cannot then occur separately. The theory of language acquisition where the child's acquisition of grammar occurs along with the semantic acquisition needs to be considered.

As already mentioned $(\S 1$.), the Chomskyan approach to grammar renders input as something that accommodates our innate codified grammar. If such contentions were interpreted as rigidly as they were posed, one could deduce that all utterances used regularly by us do not violate particular language's syntactic constraints. As anticipated, there are numerous examples in adult speech where this is not the case. The examples of such constructions are provided by Pinker and Jackendoff (2005: 220):

(2)

a) Off with his head! Into the trunk with you! (only PP and NP)

b) How about a cup of coffee? How about we have a little talk? ("How about" X?)

c) What, me worry? Him in an accident? (Mad Magazine construction)

d) One more beer and l'm leaving. (NP and a sentence)

1 Although not explicitly working in this framework, a similar conclusion is provided by Giegerich (2005) for adjective-noun constructions with associative adjectives. 
e) The more I read, the less I understand. (covariational-conditional)

Again, the existence and regularity of these constructions poses a great challenge for the generative framework for several reasons. Apart from the aforementioned issue of their location in the lexicon-syntax dichotomy, a major problem for the nativist approach would be to explain how these constructions emerged in language in the first place and how they are learned or stored (depending on the module of language to which they are assigned). Innate grammatical rules would have to be broken in order for these construction to be learned, while storing them in the lexicon would require a huge amount of memory being reserved for storing each possible instantiation. At the same time, the cases in (2) represent a major point of interest for and are easily integrated into various instantiations of Construction Grammar (inter alia, Goldberg 1995 \& 2006, Kay \& Fillmore 1999, van Trijp et al. 2012, van Trijp 2016). One of the main points of all Construction Grammars is that language consists of learned pairings of form and meaning with varying degrees of specificity and the number of these pairings is continuously extended through exposure to language and generalizations drawn from this exposure.

Tomasello (2000) provides similar examples that prove the human capacity for acquisition of "highly abstract" and yet productive constructions. Similar to the "Mad Magazine" construction is the incredulity construction posed in exclamatory fashion, with the non-finite verb and subject in the accusative case: Him be a doctor! My mother ride a motorcycle! (2000: 236). There are other syntactic idiosyncrasies listed by Tomasello (2000: 237) such as:

(3)

a) It's amazing the people you see here. It's ridiculous how long it takes. (nominal extraposition construction)

b) I wouldn't live in Boston, let alone in New York. She won't ride the stationary bike, let alone lift weights. ('let alone' construction (Fillmore et al. 1988))

The implication of these problematic constructions seems to be that learning occurs "from input", and not "with input". The distinction becomes important since it means that input is not something that merely adheres to the already innate grammatical rules. If anything, it is grammar that adheres to the input here. It is viable to assume that certain segment of language might be learned through "imitation". Moreover, the assumption that children's analogical skills are the main language learning method becomes justified with the existence of these idiosyncratic constructions, such as the "let alone" construction, which are claimed to be acquired in the same way as the canonical syntactic constructions, such as the transitive and the ditransitive construction. At first, the child learns the constructions as isolated cases, but later realizes their productive potential. As Tomasello puts it, "there is continuity not of structures [...] but there is continuity of process in the sense that the processes of learning and abstraction are the same wherever and whenever they are applicable..." (2000: 237).

Another piece of evidence comes from the children's early speech. Innate grammar presumes that grammatical errors basically do not exist. It is as if children were equipped with a particular word order which they so obediently practice (not to mention the existence of various word orders across languages). For instance, research has shown that children tend to make inversion mistakes in formation of wh-questions. A question "Why can't they go?" is often substituted with "Why they can't go?" (Tomasello 2008: 81). Of course, the question is often formed without the mistakes in grammar. Nevertheless, the only thing inherent to child's language is inconsistency and not the supposed grammatical rulebook. Undoubtedly, "obedience" of grammatical rules will eventually prevail, but through practice and habit, rather than innateness. The inversion errors in wh-question may be the consequence of lacking input in these matters (questions being less used than statements in adult speech). Naturally, the nativist account dismisses the fact that frequency of input or the "motherese" play any relevant role in the acquisition of language. Even if the interpretation takes a different direction, where the assumption is that passive constructions and wh-questions are heard just as much in the input as statements, the problem remains for the nativist account to explain the longer period of time that the acquisition of these constructions requires (Tomasello 2008: 84). 
A research carried out by Keren-Portnoy and Keren on toddlers showed that "the rate of learning new verbs in a structure is a function of the stage of acquisition of that particular structure rather than of the stage of syntactic development in general or the cognitive system (or the brain) in general" (2011: 427). The important thing to note is that the syntax seems to be acquired gradually. It was evident from the word-order errors made by children in clause formation that the acquisition was gradual since the errors were reducing through time. Greater amount of structures already acquired accelerated the acquisition process of new structures. This should certainly not be interpreted as a confirmation of the children's syntactic endowment, but as evidence for children's analytical approach to language and grammar upon acquisition.

\section{Conclusion}

Two of the most renowned theories of language acquisition were outlined and discussed in the paper, with the focus on syntactic evidence. Nevertheless, the definition of language acquisition as such was not provided, although it is often central for the debate of the issue, as it often differs between the two accounts as well. For instance, we may argue that process of language acquisition has finished when the learner can truly understand the messages conveyed in various communicative situations. However, this line of reasoning leads us to conclude that process of acquisition is never-ending. Language itself is in the process of constant changes, with its lexicon being extended every day with new words, phrases and idioms. While the argument may appear as somewhat arbitrary and "unfair" in terms of our discussion, the legitimacy of it is difficult to refute, as it illustrates the complexity of language acquisition and its theoretical definition. From the discussion it becomes apparent that both theories have difficulty concurring on the matter of when the language acquisition truly ends. For an illustration of comprehensive problems, Jackendoff uses the example at Logan Airport in Boston where the sign said Every airplane does not carry pets (2011: 198). The adult person that encounters this sign can deduce two possible interpretations: one is that "none of the airplanes carries pets", and the other that "not every airplane carries pets". The adult person which is both syntactically and semantically competent by now is suddenly having problems with the extrapolation of meaning. The tree diagram of this sentence would not be helpful as well since it would not reveal more than one possibility. At this point, the only thing that the person can use to deduce the meaning is logic, and not their linguistic competence. This example may help us in understanding of the language acquisition process in children. If the child had encountered this sign it would have to rely on their analogical skillset rather than supposed "innate grammar". The "acquisition" will then depend on the logical process of unlocking its elusive meaning. The polysemy of the airport sign is rooted in the sign's defective logical construction. The fact that the adult will have trouble in unlocking the meaning of the sign only confirms that the nature of acquisition depends on extra-linguistic cues. This particular situation is identical to almost every situation in which a toddler encounters a new syntactic construction. The child will, just like an adult person, use previously acquired knowledge and analogical skills to deduce its meaning and in the case of failure - the child will figure out and memorize the next best thing - the new syntactic construction, particular word's meaning etc. The second important debate related to language acquisition, besides the problematic definition of the process, is found in the question of language emergence. Something that had never existed suddenly appeared among the humanoid race. Nevertheless, the speculative part about the route of evolution can equally be applied to other cognitive capacities developed in humans. Moreover, it is not that language's emergence was so sudden after all - highly developed communication systems are found across animal kingdom. The advocates of cognition-language interdependency claim that language originated from unified voicing, emotional intelligence and concept-understanding (Perlovsky 2009: 519). Vygotsky, on the other hand, argued that "language and cognition originate independently but become interdependent" (1934/1962, cited in Harley 2014: 89). Language as we define it today is often claimed to be far more intricate and complicated than communication systems found among animals. This overestimation of language's complexity is often given by nativists. Provided that this characterization is a legitimate one, it is still quite possible, if not obvious, that this complexity may have emerged as a byproduct of human intelligence and evolved cognition.

The estimation of language's complexity might very well be the "apple of discord" between the two accounts discussed in the paper. Within the nativist tradition, language and grammar are seen as too complex to be learned with such ease - 
which is why they must be innate. The advocates of the usage-based account perceive the acquisition of syntax as a piecemeal process, evidently such because of the countless errors made during the acquisition. Grammar is indeed complex, but mastered easily because of the advanced cognition children are equipped with - children's use of "...mentalistic cues - such as eye gaze and emotional expression (Bloom 2001: 1100)" and the "attainment of object permanence" (O'Grady \& Dobrovolsky 1997: 81) being crucial mechanisms of language acquisition. Some of the evidence provided in the paper can be interpreted from both standpoints, mostly because the assessment of acquisition speed is arbitrary. The process of language acquisition is considered too rapid to be relying on cognition by nativists, and too slow to be regarded innate by advocates of the usage-based account. In this paper, we argued that cognition holds the key to language acquisition. Syntactic marking is mastered individually by making logical generalizations using the received input. The child is forced to learn the language of its environment and we can assume that the child's entire cognition is directed towards interpretation of the surrounding language. To us, nativism does not appear as a valid answer to the problem of acquisition, and it is partly so because of this adamant characterization of language as being separate from cognition.

\section{References}

[1] Abels, K., \& Neeleman, A. (2010). Nihilism masquerading as progress. Lingua, 120(12), 2657-2660.

[2] Bloom, P. "Précis of How Children Learn the Meanings of Words." Behavioral and Brain Sciences, 24 (2001): 1095-1103.

[3] Bod, L. W. M. (2008). From exemplar to grammar: Integrating analogy and probability in language learning. Institute for Logic, Language and Computation (ILLC), University of Amsterdam.

[4] Boyd, J. K., \& Goldberg, A. E. (2009). Input Effects within a Constructionist Framework. The Modern Language Journal, 93(3), 418-429.

[5] Brown, Roger W. "Linguistic determinism and the part of speech.". The Journal of Abnormal and Social Psychology. 55.1 (1957): 1-5.

[6] Butterworth, B. "Commentary on "how can Syntax Support Number Word Acquisition?" by Syrett, Kristen, Musolino, Julien and Gelman, Rochel." Language Learning and Development 8.2 (2012): 186-9.

[7] Bybee, J. L. (2006). From usage to grammar: The mind's response to repetition. Language, 82(4), 711-733.

[8] Chomsky, N."A Review of B.F. Skinner's Verbal Behaviour." Language (1959): 48-63.

[9] Chomsky, N. (1957). Syntactic Structures. The Hague, Paris: Mouton Publishers.

[10] Chomsky, N. (1965). Aspects of the Theory of Syntax. Cambridge, Massachusetts: MIT Press.

[11] Chomsky, N. (2002). Syntactic Structures. New York: Mouton de Gruyter, 2nd edition.

[12] Chomsky, N. (2006). Language and Mind. Cambridge: Cambridge University Press.

[13] Cook V.J. \& Newson M. (2007). Chomsky's Universal Grammar. Blackwell Publishing.

[14] Culicover, P. W., \& Jackendoff, R. (2005). Simpler syntax. Oxford ; New York: Oxford University Press.

[15] Descartes, R. (1984). "Discourse on the Method", in The Philosophical Writings of Descartes, Vol. Il. Cambridge: Cambridge University Press.

[16] Evans, Nicholas and Levinson, Stephen. "The Myth of Language Universals: Language diversity and its importance for cognitive science." Behavioral and Brain Sciences (2009): 1-62.

[17] Everett, D. L. (2005). Cultural Constraints on Grammar and Cognition in Pirahã: Another Look at the Design Features of Human Language. Current Anthropology, 46(4), 621-646.

[18] Everett, D. L. (2007). Cultural constraints on grammar in Pirahã: A reply to Nevins, Pesetsky, and Rodrigues (2007). Online: Http://Ling. Auf. Net/lingBuzz/000427.

[19] Ferreira, F., Bailey, K. G., \& Ferraro, V. (2002). Good-enough representations in language comprehension. Current Directions in Psychological Science, 11(1), 11-15.

[20] Ferreira, F., \& Patson, N. D. (2007). The "Good Enough" Approach to Language Comprehension. Language and Linguistics Compass, 1(1-2), 71-83. 
[21] Fillmore, C. J., Kay, P., \& O'Connor, M. C. (1988). Regularity and Idiomaticity in Grammatical Constructions: The Case of Let Alone. Language, 64(3), 501-538.

[22] Frank, S. L., Bod, R., \& Christiansen, M. H. (2012). How hierarchical is language use? Proceedings of the Royal Society B: Biological Sciences, 279(1747), 4522-4531.

[23] Futrell, R., Stearns, L., Everett, D. L., Piantadosi, S. T., \& Gibson, E. (2016). A Corpus Investigation of Syntactic Embedding in Pirahã. PLOS ONE, 11(3), e0145289.

[24] Giegerich, H. J. (2005). Associative adjectives in English and the lexicon-syntax interface. Journal of Linguistics, 41(03), 571.

[25] Goldberg, A. E. (1995). Constructions: a construction grammar approach to argument structure. Chicago: University of Chicago Press.

[26] Goldberg, A. E. (2006). Constructions at work: the nature of generalization in language. Oxford ; New York: Oxford University Press.

[27] Goldberg, A. E., Casenhiser, D. M., \& Sethuraman, N. (2004). Learning argument structure generalizations. Cognitive Linguistics, 15(3), 289-316.

[28] Harley, T.A. (2014). The Psychology of Language: From Data to Theory. Fourth Edition. New York: Psychology Press

[29] Hauser, Marc D., Chomsky, Noam and Fitch, W. Tecumseh. (2002). "The Faculty of Language: What Is It, Who Has It, and How Did It Evolve?" Science. 298. 5598, 1569 - 1579.

[30] Jackendoff, R. (2007). A Parallel Architecture perspective on language processing. Brain Research, 1146, 222.

[31] Jackendoff, R. (2008). Construction after Construction and its Theoretical Challenges. Language, 84(1), 8-28.

[32] Jackendoff, R. (2011). What is the human language faculty?: Two views. Language, 87(3), 586-624.

[33] Jackendoff, R., \& Audring, J. (2016). Morphological schemas: Theoretical and psycholinguistic issues. The Mental Lexicon, 11(3), 467-493.

[34] Kay, P., \& Fillmore, C. J. (1999). Grammatical constructions and linguistic generalizations: the What's $X$ doing $Y$ ? construction. Language, 1-33.

[35] Keenan, E. L., \& Stabler, E. P. (2010). Language variation and linguistic invariants. Lingua, 120(12), 2680-2685.

[36] Keren-Portnoy, Tamar, and Keren Michael. (2011). "The Dynamics of Syntax Acquisition: Facilitation between Syntactic Structures." Journal of Child Language 38.2, 404-32.

[37] Levinson, S. C., \& Evans, N. (2010). Time for a sea-change in linguistics: Response to comments on "The Myth of Language Universals." Lingua, 120(12), 2733-2758.

[38] Lillo-Martin, Diane, and Ronice Müller de Quadros. (2011). Acquisition of the syntax-discourse Interface: The Expression of Point of View. Lingua 121.4, 623-36.

[39] Makkai, A. (1972). Idiom Structure in English. The Hague: Mouton \& Co. N.V. Newmark, P.

[40] Mendívil-Giró, J.-L. (to appear). Is Universal Grammar ready for retirement? Journal of Linguistics.

[41] Messenger, K., Yuan, S. \& Fisher, C. (2015). Learning Verb Syntax via Listening: New Evidence From 22Month-Olds, Language Learning and Development 11. 4, 356-356.

[42] Müller, S. (2013). Unifying everything: Some remarks on simpler syntax, construction grammar, minimalism, and HPSG. Language, 89(4), 920-950.

[43] Nevins, A. (2009). On formal universals in phonology. Behavioral and Brain Sciences, 32(05), 461.

[44] Nevins, A., Pesetsky, D., \& Rodrigues, C. (2009a). Evidence and argumentation: A reply to Everett (2009). Language, 85(3), 671-681.

[45] Nevins, A., Pesetsky, D., \& Rodrigues, C. (2009b). Nevins, Pesetsky, Rodrigues_Pirahã exceptionality - A Reassessment. Language, 86(2), 355-404.

[46] O'Grady, W. Dobrovolsky, M. (1997). Contemporary Linguistics: An Introduction. Third Edition. Boston/New York: Bedford/St. Martin's. 
[47] O'Grady, W. \& Whan Cho, S. (2016). First language acquisition. In O'Grady, William \& Archibald, John (Eds.), Contemporary Linguistic Analysis: An Introduction (323-361). Toronto: Pearson Education, Inc.

[48] Perlovsky, Leonid. "Language and Emotions: Emotional Sapir-Whorf Hypothesis." Neural Networks 22.5 (2009): 518-26.

[49] Pinker, Steven. (1995). The Language Instinct: The New Science of Language and Mind, Penguin, Harmondsworth.

[50] Pinker, Steven and Jackendoff Ray. (2005). "The Nature of the Language Faculty and its Implications for Evolution of Language: Reply to Fitch, Hauser, and Chomsky." Cognition: International Journal of Cognitive Science $97.2,211-25$.

[51] Reuland, E., \& Everaert, M. (2010). Reaction to: The Myth of Language Universals and cognitive science"Evans and Levinson's cabinet of curiosities: Should we pay the fee? Lingua, 120 (12), 2713-2716.

[52] Skinner, B.F. (1957). Verbal Behavior. NY: Prentice Hall.

[53] Snyder, W. (2007). Child Language: The Parametric Approach. Oxford: Oxford University Press.

[54] Theakston, Anna L., et al. (2004). "Semantic Generality, Input Frequency and the Acquisition of Syntax." Journal of Child Language 31.1, 61-99.

[55] Tomasello, M. (2000). Do young children have adult syntactic competence? Cognition, 74, 209-253.

[56] Tomasello, M. (2003). Constructing a Language: A Usage-Based Theory of Language Acquisition. Harvard University Press.

[57] Tomasello, M. (2008) "The Usage-based theory of language acquisition". In Bavin, E, (Ed.) The Cambridge handbook of child language pp.69-88.

[58] Tomasello, Michael, and Silke Brandt. (2009). "Flexibility in the Semantics and Syntax of Children's Early Verb use." Monographs of the Society for Research in Child Development 74.2, 113-26.

[59] van Trijp, R. (2016). Chopping down the syntax tree: What constructions can do instead. Belgian Journal of Linguistics, 30, 15-38.

[60] Van Trijp, R., Steels, L., Beuls, K., \& Wellens, P. (2012). Fluid construction grammar: The new kid on the block. In Proceedings of the Demonstrations at the 13th Conference of the European Chapter of the Association for Computational Linguistics (pp. 63-68). Association for Computational Linguistics.

[61] Vinogradov, V. V. (1986). On the main types of phraseological units in the Russian language. Moscow: Science.

[62] Vygotsky, L. (1934). Thought and language (Trans. E. Hanfman \& G. Vakar, 1962). Cambridge, MA: MIT Press.

[63] Yin, Bin, and Kaiser, Elsi. (2013). Second Language Learners' Knowledge of Syntax in the Acquisition of Aspectual Semantics. Procedia - Social and Behavioral Sciences 9, 454-63. 